\title{
COMMON FIXED POINTS OF COMPATIBLE MAPPINGS
}

\section{S.M. KANG and Y.J. CHO}

\author{
Departinent of Mathematics \\ Gyeongsang National Universily \\ Jinju 660-701 \\ Korea

\section{G. JUNGCK} \\ Department of Mathematics \\ Bradley Universily \\ Peoria, Illinois 61625 U.S.A.
}

(Received October 19, 1988 and in revised form Se ptember 27, 1988)

ABSTRACT. In this paper, we present a common fixed point theorem for compatible mappings, which extends the results of Ding, Diviccaro-Sessa and the third author.

KEY WORDS AND PHRASES. Common fixed points, commuting mappings, weakly commuting mappings and compatible mappings.

1980 AMS MATHEMATICS SUBJECT CLASSIFICATION CODE. $54 \mathrm{H} 25$.

\section{INTRODUCTION.}

In [1], the concept of compatible mappings was introduced as a generalization of commuting mappings. The utility of compatibility in the context of fixed point theory was demonstrated by extending a theorem of Park-Bae [2]. In [3], the third author extended a result of Singh-Singh [4] by employing compatible mappings in lieu of commuting mappings and by using four functions as opposed to three. On the other hand, Diviccaro-Sessa [5] proved a common fixed point theorem for four mappings, using a well known contractive condition of Meade-Singh [6] and the concept of weak commutativity of Sessa [7]. Their theorems generalize results of Chang [8], Imdad Khan [9], Meade-Singh [6], Se ssa-Fisher [10] and Singh-Singh [4].

In this paper, we extend the results of Ding [11], Diviccaro-Sessa [5] and the third author [3].

The following Definition 1.1 is given in [1].

DEFINITION 1.l. Let $A$ and $B$ be mappings from a metric space $(X, d)$ into itself. Then $A$ and $B$ are said to be compatible if $\lim _{n+\infty} d\left(A B x_{n}, B A x_{n}\right)=0$ whenever $\left\{x_{n}\right\}$ is a sequence in $X$ such that $\lim _{\rightarrow \infty} A x_{n}=\lim _{n \rightarrow \infty} B x_{n}=z$ for some $z$ in $X$.

Thus, if $d\left(A B x_{n}, B A x_{n}\right) \rightarrow 0$ as $d\left(A x_{n}, B x_{n}\right) \rightarrow 0$, then $A$ and $B$ are compatible. 
Mappings which commute are clearly compatible, but the converse is false. S. Sessa [7] generalized commuting mappings by calling mappings $A$ and $B$ from a metric space ( $X, d)$ into itself a weakly commuting pair if $d(A B x, B A x) \leqslant d(A x, B x)$ for $d 1 l x$ in $X$. Any weakly commuting pair are obviously compatible, but the converse is false [3]. See [1] for other examples of the compatabile pairs which are not weakly commutative and hence not commuting pairs.

LEMMA 1.1 ([1]). Let $A$ and $B$ be compatible mappings from a metric space (X,d) into itself. Suppose that $\lim _{n \rightarrow \infty} A x_{n}=\lim _{n \rightarrow \infty} B x_{n}=z$ for some $z$ in $X$.

Then $\lim \mathrm{BAx}_{\mathrm{n}}=\mathrm{Az}$ if $\mathrm{A}$ is continuous.

$n+\infty$

2. A FIXED POINT THEOREM.

Throughout this paper, suppose that the function $D:[0, \infty)^{5}+(0, \infty)$ satisfies the following conditions:

(1) Is nondecreasing and upper semicontinuous in each coordinate variable,

(2) For each $t>0, \psi(t)=\max \{\Phi(0,0, t, t, t), \Phi(t, t, t, 2 t, 0)$, $\Phi(t, t, t, 0,2 t)\}<t$.

LEMMA 2.1 ([12]). Suppose that $\Psi:[0, \infty)+[0, \infty)$ is nondecreasing and upper semicontinuous from the right. If $\Psi(t)<t$ for every $t>0$, then 1 im $\Psi^{n}(t)=0$, where $\Psi^{n}(t)$ denotes the composition of $\Psi(t)$ with itself $n-t$ imes.

Now, we are ready to state our main Theorem.

THEOREM 2.2. Let $A, B, S$, and $T$ be mappings from a complete metric space (X,d) into itself. Suppose that one of $A, B, S$ and $T$ is continuous, the pairs $A, S$ and $B, T$ are compatible and that $A(X) \subset T(X)$ and $B(X) \subset S(X)$. If the inequality

$$
d(A x, B y)<\Phi(d(A x, S x), d(B y, T y), d(S x, T y), d(A x, T y), d(B y, S x))
$$

holds for all $x$ and $y$ in $X$, where satisfies (1) and (2), then $A, B, S$ and $T$ have a unique common fixed point in $X$.

PROOF. Let $x_{0} \in X$ be given. Since $A(X) \subset T(X)$ and $B(X) \subset S(X)$, we can choose $x_{1}$ in $X$ such that $y_{1}=T x_{1}=A x_{0}$ and, for this point $x_{1}$, there exists a point $x_{2}$ in $X$ such that $\mathrm{y}_{2}=\mathrm{Sx}_{2}=\mathrm{Bx}_{1}$ and so on. Inductively, we can define a sequence $\left\{\mathrm{y}_{\mathrm{n}}\right\}$ in $\mathrm{X}$ such that

$$
\mathrm{Y}_{2 \mathrm{n}+1}=\mathrm{Tx}_{2 \mathrm{n}+1}=\mathrm{Ax}_{2 \mathrm{n}} \text { and } \mathrm{y}_{2 \mathrm{n}}=\mathrm{Sx}_{2 \mathrm{n}}=\mathrm{Bx}_{2 \mathrm{n}-1} \cdot
$$

By $(2.2)$ and $(2.3)$, we have

$$
\begin{aligned}
d\left(y_{2 n+1}, y_{2 n+2}\right)= & d\left(A x_{2 n}, B x_{2 n+1}\right) \\
< & \Phi\left(d\left(A x_{2 n}, S x_{2 n}\right), d\left(B x_{2 n+1}, T x_{2 n+1}\right), d\left(S x_{2 n}, T x_{2 n+1}\right),\right. \\
& \left.d\left(A x_{2 n}, T x_{2 n+1}\right), d\left(B x_{2 n+1}, S x_{2 n}\right)\right) \\
< & \Phi\left(d\left(y_{2 n+1}, y_{2 n}\right), d\left(y_{2 n+2}, y_{2 n+1}\right), d\left(y_{2 n}, y_{2 n+1}\right),\right. \\
& \left.0, d\left(y_{2 n+2}, y_{2 n}\right)\right) \\
< & \Phi\left(d \left(y_{2 n}, y_{2 n+1}, d\left(y_{2 n+1}, y_{2 n+2}\right), d\left(y_{2 n}, y_{2 n+1}\right),\right.\right. \\
& \left.0, d\left(y_{2 n}, y_{2 n+1}\right)+d\left(y_{2 n+1}, y_{2 n+2}\right)\right) .
\end{aligned}
$$


If $d\left(v_{2 n+1}, y_{2 n+2}\right)>d\left(y_{2 n}, y_{2 n+1}\right)$ in the above Inequality, then we have

$$
\begin{aligned}
d\left(y_{2 n+1}, y_{2 n+2}\right) \leqq & \Phi\left(d\left(y_{2 n+1}, y_{2 n+2}\right), d\left(y_{2 n+1}, y_{2 n+2}\right),\right. \\
& \left.\left.d\left(y_{2 n+1}\right), y_{2 n+2}\right), 0,2 d\left(y_{2 n+1}, y_{2 n+2}\right)\right) \\
\leqq & \Psi\left(d\left(y_{2 n+1}, y_{2 n+2}\right)\right)<d\left(y_{2 n+1}, y_{2 n+2}\right),
\end{aligned}
$$

which is a contradiciton. Thus,

$$
\begin{aligned}
d\left(y_{2 n+1}, y_{2 n+2}\right) \leqslant & b\left(d\left(y_{2 n}, y_{2 n+1}\right), d\left(y_{2 n}, y_{2 n+1}\right) d\left(y_{2 n}, y_{2 n+1}\right),\right. \\
& \left.0,2 d\left(y_{2 n}, y_{2 n+1}\right)\right) \\
& \Psi\left(d\left(y_{2 n}, y_{2 n+1}\right)\right) .
\end{aligned}
$$

Similarly, we have

$$
d\left(y_{2 n+2}, y_{2 n+3}\right) \leqslant \Psi\left(d\left(y_{2 n+1}, y_{2 n+2}\right)\right) \text {. }
$$

It follows from $(2.4)$ and $(2.5)$ that

$$
d_{n}=d\left(y_{n}, y_{n+1}\right)<\Psi\left(d\left(y_{n-1}, y_{n}\right)\right) \leqslant \ldots \leqslant \psi^{n-1}\left(d_{(}\left(y_{1}, y_{2}\right)\right) \text {. }
$$

By (2.6) and Lemma 2.1 , we obtain

$$
\lim _{n \rightarrow \infty} d_{n}=0 \text {. }
$$

In order to show that $\left\{y_{n}\right\}$ is a Cauchy sequence, it is sufficient to show that $\left\{y_{2 n}\right\}$ is a Cauchy sequence. Suppose that $\left\{y_{2 n}\right\}$ is not a Cauchy sequence. Then there is an $\varepsilon>0$ such that, for each even integer $2 k$, there exist even integers $2 \mathrm{~m}(\mathrm{k})$ and $2 n(k)$ such that

$$
\mathrm{d}\left(\mathrm{y}_{2 \mathrm{~m}(\mathrm{k})}, \mathrm{y}_{2 \mathrm{n}(\mathrm{k})}\right)>\varepsilon \text { for } 2 \mathrm{~m}(\mathrm{k})>2 \mathrm{n}(\mathrm{k})>2 \mathrm{k} \text {. }
$$

For each even integer $2 k$, let $2 \mathrm{~m}(\mathrm{k})$ be the least even integer exceeding

$2 n(k)$ satisfying $(2.8)$, that is,

$$
d\left(y_{2 n(k)}, y_{2 m(k)-2}\right)<\varepsilon \text { and } d\left(y_{2 n(k)}, y_{2 m(k)}\right)>\varepsilon \text {. }
$$

The $n$, for each even integer $2 k$,

$$
\varepsilon<d\left(y_{2 n(k)}, y_{2 m(k)}\right)<d\left(y_{2 n(k)}, y_{2 m(k)-2}\right)+d_{2 m(k)-2}+d_{2 m(k)-1} \cdot
$$

It follows from (2.7) and (2.9) that

$$
\lim _{k \rightarrow \infty} d\left(y_{2 n}(k), y_{2 m(k)}\right)=\varepsilon .
$$

By the triangle inequality,

$$
\begin{aligned}
& \left|d\left(y_{2 n(k)}, y_{2 m(k)-1}\right)-d\left(y_{2 n(k)}, y_{2 m(k)}\right)\right| \leqslant d_{2 m(k)-1} \text { and } \\
& \left|d\left(y_{2 n(k)+1}, y_{2 m(k)-1}\right)-d\left(y_{2 n(k)}, y_{2 m(k)}\right)\right|<d_{2 m(k)-1}+d_{2 n(k)} \text {. }
\end{aligned}
$$

From $(2.7)$ and $(2.10)$, as $k \rightarrow \infty$,

$$
d\left(y_{2 n(k)}, y_{2 m(k)-1}\right) \rightarrow c \text { and } d\left(y_{2 n(k)+1}, y_{2 m(k)-1}\right)+\varepsilon_{\bullet}
$$


By $(2.2)$ and $(2.3)$, we have

$$
\begin{aligned}
d\left(y_{2 n(k)}, y_{2 m(k)}\right) \leqslant & d_{2 n(k)}+d\left(A x_{2 n(k)}, B x_{2 m(k)-1}\right) \\
\leqslant & d_{2 n(k)}+b\left(d_{2 n(k)}, d_{2 m(k)-1}, d\left(y_{2 n(k)}, y_{2 m(k)-1}\right),\right. \\
& \left.d\left(y_{2 n(k)+1}, y_{2 m(k)-1}\right), d\left(y_{2 m(k)}, y_{2 n(k)}\right)\right) .
\end{aligned}
$$

Since $\Phi$ is upper semicontinuous,

$$
\varepsilon<\Phi(0,0, \varepsilon, \varepsilon, \varepsilon)<\epsilon \text { as } k \rightarrow \infty,
$$

which is a contradiction. Hence $\left\{y_{n}\right\}$ is a Cauchy sequence and it converges to some point $z$ in $X$. Consequently the subsequences $\left\{A x_{2 n}\right\},\left\{S x_{2 n}\right\},\left\{B x_{2 n-1}\right\}$ and $\left\{T x_{2 n-1}\right\}$ converge to $z$. Suppose that $S$ is continuous. Since $A$ and $S$ are compatible, Lemma 1.2 implies that

By (2.2), we obtain

$$
\mathrm{SSx}_{2 \mathrm{n}} \text { and } \mathrm{ASx}_{2 \mathrm{n}} \rightarrow \mathrm{Sz}
$$

$$
\begin{aligned}
d\left(A S x_{2 n}, B x_{2 n-1}\right)< & d\left(d\left(A S x_{2 n}, S S x_{2 n}\right), d\left(B x_{2 n-1}, T x_{2 n-1}\right),\right. \\
& \left.d\left(S S x_{2 n}, T x_{2 n-1}\right), d\left(A S x_{2 n}, T x_{2 n-1}\right) d\left(B x_{2 n-1}, S S x_{2 n}\right)\right)
\end{aligned}
$$

Letting $n+\infty$, we have

$$
d(S z, z)<p(0,0, d(S z, z), d(S z, z), d(z, S z)),
$$

so that $z=S z$. By (2.2), we also obtain

$$
\begin{aligned}
d\left(A z, B x_{2 n-1}\right)< & P\left(d(A z, S z), d\left(B x_{2 n-1}, T x_{2 n-1}\right), d\left(S z, T x_{2 n-1}\right),\right. \\
& \left.d\left(A z, T x_{2 n-1}\right), d\left(B x_{2 n-1}, S z\right)\right) .
\end{aligned}
$$

Letting $\mathbf{n} \rightarrow \infty$, we have

$$
d(A z, z) \leqslant d(d(A z, S z), 0, d(S z, z), d(A z, z), d(z, S z)),
$$

so that $z=A z$. Since $A(X) \subset T(X), z \in T(X)$ and hence there exists a point $w$ in $X$ such that $z=A z=T w$.

$$
d(z, B w)=d(A z, B w)<P(J, d(B w, T w), d(S z, T w), d(A z, T w), d(B w, z)),
$$

which implies that $z=B w$. Since $B$ and $T$ are compatible and $T w=B w=z, d(T B w, B T w)$

$=0$ and hence $\mathrm{Tz}=\mathrm{TBw}=\mathrm{BTw}=\mathrm{Bz}$. Moreover, by $(2.2)$,

$$
d(z, T z)=d(A z, B z)<\Phi(0, d(B z, T z), d(z, T z), d(z, T z), d(B z, z)),
$$

so that $z=T z$. Therefore, $z$ is a common fixed point of $A, B, S$ and $T$. Similarly, we can complete the proof in the case of the continuity of $T$. Now, suppose that $A$ is continuous. Since $A$ and $S$ are compatible, Lemma 1.2 implies that

$$
\mathrm{AAx}_{2 \mathrm{n}} \text { and } \mathrm{SAx}_{2 \mathrm{n}}+\mathrm{Az} \text {. }
$$

By $(2.2)$, we have

$$
\begin{aligned}
& d\left(A_{2 n}, B x_{2 n-1}\right)<D\left(d\left(A_{2 n}, S A x_{2 n}\right), d\left(B x_{2 n-1}, T x_{2 n-1}\right),\right. \\
& \left.d\left(\operatorname{SAx}_{2 n}, T x_{2 n-1}\right), d\left(A_{2 A x}, T x_{2 n-1}\right), d\left(B x_{2 n-1}, S A x_{2 n}\right)\right) \text {. }
\end{aligned}
$$

Letting $n+\infty$, we obtain

$$
d(A z, z)<\Phi(0,0, d(A z, z), d(A z, z) d(z, A z)),
$$

so that $z=A z$. Hence, there exists a poine $v$ in $X$ such that $z=A z=T v$. 


$$
\begin{aligned}
d\left(A A z_{2 n}, B v\right) \leqq & \Phi\left(d\left(A_{2 n}, S A x_{2 n}\right), d(B v, T v), d\left(S A x_{2 n}, T v\right),\right. \\
& \left.d\left(A_{2 A x_{2 n}}, T v\right) d\left(B v, S A x_{2 n}\right)\right)
\end{aligned}
$$

Letting $n \rightarrow \infty$, we have

$$
d(z, B v) \leqslant \Phi(0, d(B v, T v), d(z, T v), d(A z, T v), d(B v, z)),
$$

which implies that $z=B v$. Since. $B$ and $T$ are compatible and $T v=B v=z, d(T B v, B T v)$ $=0$ and hence $\mathrm{Tz}=\mathrm{TBv}=\mathrm{BTV}=\mathrm{Bz}$. Moreover, by $(2.2)$, we have

$$
\begin{aligned}
d\left(A x_{2 n}, B z\right)< & \Phi\left(d\left(A x_{2 n}, S x_{2 n}\right), d(B z, T z), d\left(S x_{2 n}, T z\right),\right. \\
& \left.d\left(A x_{2 n}, T z\right), d\left(B z, S x_{2 n}\right)\right) .
\end{aligned}
$$

Letting $n \rightarrow \infty, d(z, B z) \leqslant \Phi(0, d(B z, T z), d(z, T z), d(z, T z), d(B z, z))$, so that $z=$ $B z$. Since $B(X) \subset S(X)$, there exists a point $w$ in $X$ such that $z=B z=S w$.

$$
d(A w, z)=d(A w, B z)<\phi(d(A w, S w), 0, d(S w, z), d(A w, z), d(z, S w)),
$$

so that $A w=z$. Since $A$ and $S$ are compatible and $A w=S w=z, d(S B w, B S w)=0$ and hence $\mathrm{Sz}=\mathrm{SAw}=\mathrm{ASW}=\mathrm{Az}$. Therefore $z$ is a common fixed point of $A, B, S$ and $T$. Similarly, we can complete the proof in the case of the continuity of B. It follows easily from (2.2) that $z$ is a unique common fixed point of $A, B, S$ and $T$.

COROLLARY 2.3. Let $A, B, S$ and $T$ be mappings from a complete metric space (X,d) into itself. Suppose that one of $A, B, S$ and $T$ is continuous, the pairs $A, S$ and $B, T$ are compatible and that $A(X) \subset T(X)$ and $B(X) \subset S(X)$. If the inequality (2.2) holds for all $x$ and $y$ in $X$, where $\Phi$ satisfies (1) and (2.11);

$$
\psi(t)=\max \{\Phi(t, t, t, t, t), \Phi(t, t, t, 2 t, 0), \Phi(t, t, t, 0,2 t)\}<t
$$

for each $t>0$, then $A, B, S$ and $T$ have $a$ unique common fixed point in $X$.

REMARK 2.4. From Theorem 2.2 and Corollary 2.3, we extend the results of Ding [11] and Diviccaro-Sessa [5] by employing compatibility in lieu of commuting and weakly commuting mappings, respectively. Further our theorem extends also a result of Ding [11] by using one continuous function as opposed to two.

REMARK 2.5. From Theorem 2.2 defining $\Phi:[0, \infty)^{5} \rightarrow[0, \infty)$ by

$$
\Phi\left(t_{1}, t_{2}, t_{3}, t_{4}, t_{5}\right)=h \max \left\{t_{1}, t_{2}, t_{3}, l_{2}\left(t_{4}+t_{5}\right)\right\}
$$

for all $t_{1}, t_{2}, t_{3}, t_{4}, t_{5} \in[0, \infty)$ and $h \in[0,1)$, we obtain a result of the third author [3] even if one function is continuous as opposed to two.

\section{REFERENCES}

1. JUNGCK, G., Compatible mappings and common fixed points. Internat. J. Math. \& Math. Sci., 9 (1986), 771-779.

2. PARK, S. and BAE, J.S., Extensions of a common fixed point theorem of Mier and Keeler, Ark. Math., 19 (1981), 223-228. 
3. JUNGCK, G., Compatible mappings and common fixed points (2), Internat. J. Math. and Math. Sci., $11(1988), 285-288$.

4. SINGH, S.L. and SINGH, S.P., A fixed point theorem, Indian J. Pure \& Applied Math. $11(1980), 1584-1586$.

5. DIVICCARO, M.L. and SESSA,S., Some remarks on common fixed points of four mappings, Jnanabha, 15 (1985), 139-149.

6. MEADE, B.A. and SINGH, S.P., On common fixed point theorems, Bull. Austral. Math. Soc., 16 (1977), 49-53.

7. SESSA, S., On a weak commutatibity condition in fixed point considerations, Pub1. Inst. Math., 32(46) (1982), 149-153.

8. CHANG, C.C., On a fixed point theorem of contractive type, Comm. Math. Univ. St. Paul 32 (1983), 15-19.

9. IMDAD, M. and KHAN, M.S., Fixed point theorems for a class of mappings, Indian J. Pure and Applied Math., 14 (1983), 1220-1227.

10. SESSA, S. and FISHER, B., Common fixed points of weakly commuting mappings, Bul1. Polish. Acad. Sc1. Math., 35, (1987), 341-349.

11. DING, X.P., Some common fixed point theorems of commuting mappings II, Math. Seminar Note, $11(1983), 301-305$.

12. MARKOWSKI, J., Fixed point theorems for mappings with contractive iterate at a point, Proc. Ame r. math. Soc., 62 (1977), 344-348. 


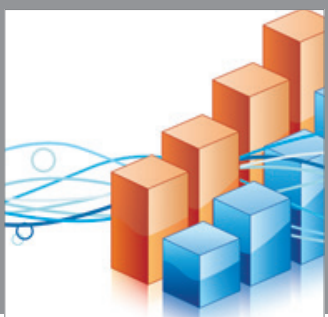

Advances in

Operations Research

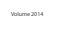

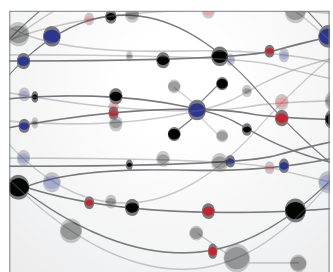

\section{The Scientific} World Journal
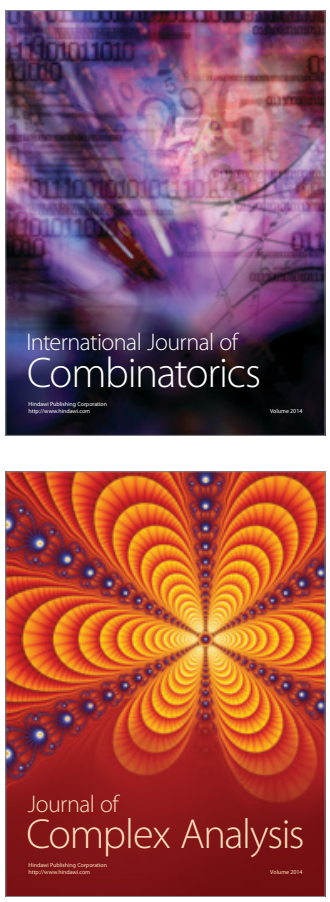

International Journal of

Mathematics and

Mathematical

Sciences
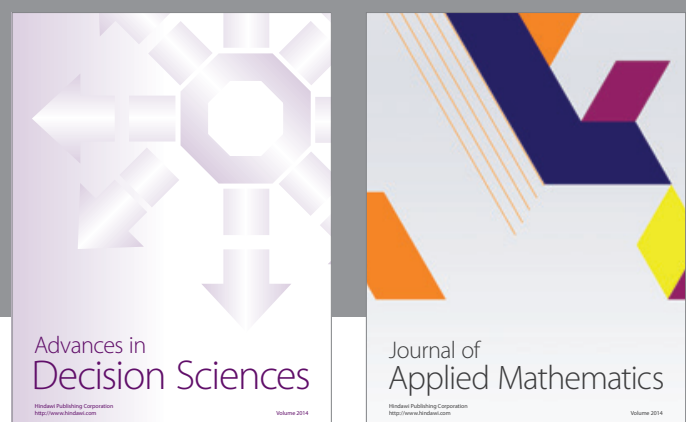

Journal of

Applied Mathematics
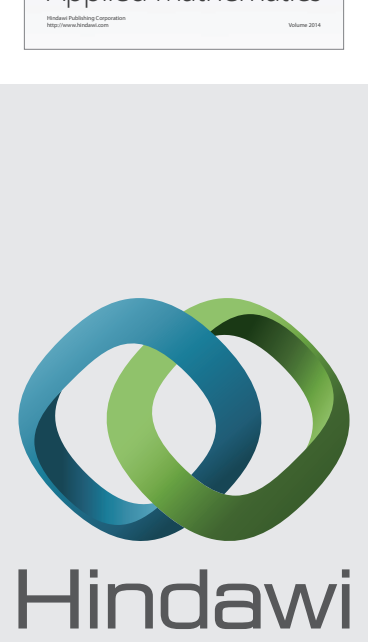

Submit your manuscripts at http://www.hindawi.com
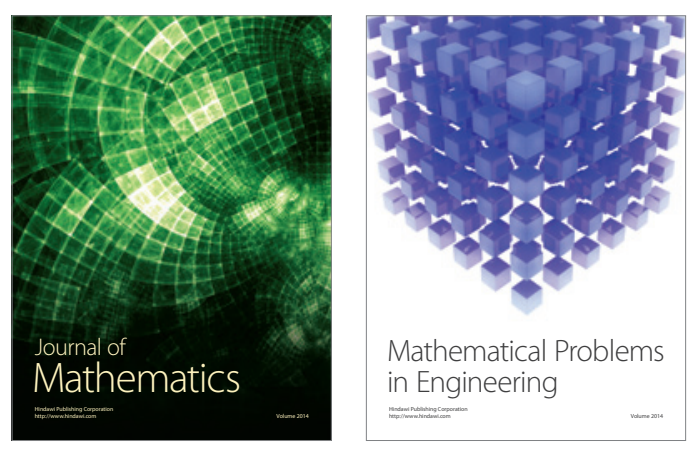

Mathematical Problems in Engineering
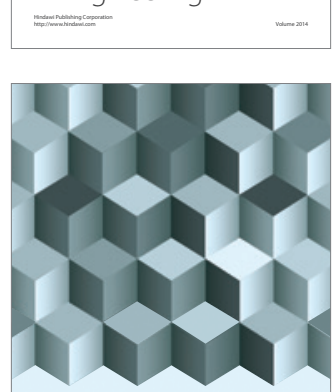

Journal of

Function Spaces
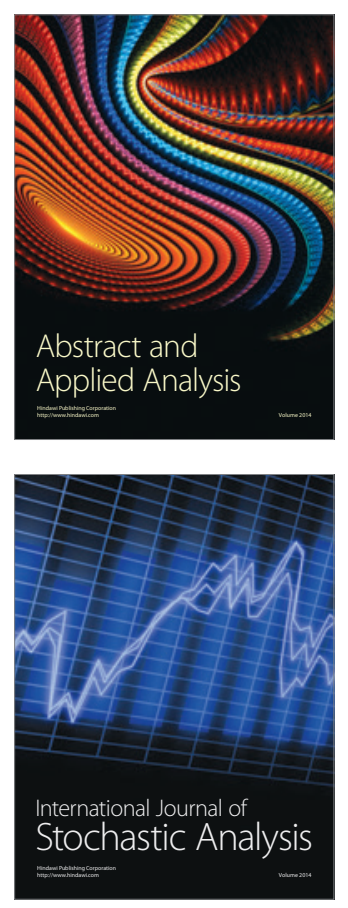

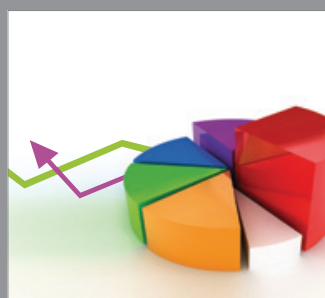

ournal of

Probability and Statistics

Promensencen
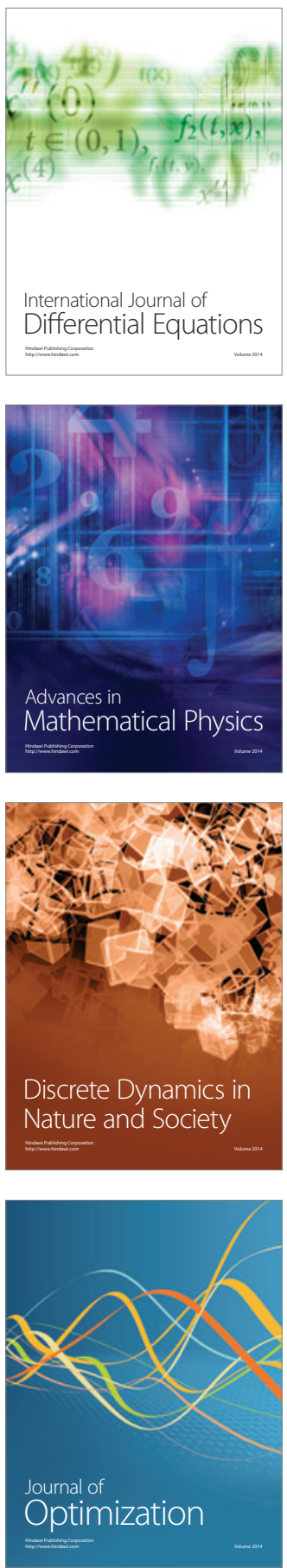